of the hepatic anlage (Fraser, 1952) or by further branching of the foregut diverticulum (Ashby, 1969).

Accessory lobes may be attached to the liver by a pedicle of the liver tissue or by a mesentery (Johnstone, 1965). For the accessory lobe to be viable it should have the hepatic artery, hepatic vein, portal vein and bile duct, which usually communicate through the liver, but occasionally may have extrahepatic connection as in the present case.

All reported cases of this phenomenon, and their symptoms, are summarized in Table 1.

Late presentation is due to gradual worsening of the circulation in the lobe. All the six cases reported were diagnosed at operation. Pre-operative diagnosis can be made by using one or more techniques of pneumoperitoneum, percutaneous hepatic cholangiography, splenic portography, regional arteriography, coelioscopy and scintillation scanning (Omanik and Jablonsky, 1972; Llorente and Dardik, 1971).
References

AshBy, E.C. (1969) Accessory liver lobe attached to the gall bladder. British Journal of Surgery, 56, 311.

Fisher, W., cited by Cullen, T.S. (1925) Accessory lobes of the liver, an accessory hepatic lobe springing from the surface of the gall bladder. Archives of Surgery, 11, 718.

Fraser, C.G. (1952) Accessory lobes of the liver. Annals of Surgery, 135, 127.

JoHnstone, G. (1965) Accessory lobe of liver presenting음 through a congenital deficiency of anterior abdominal $\frac{\omega}{5}$ wall. Archives of Disease in Childhood, 40, 541.

Levi, M.N., CReQue, L. \& Cinque, S. (1969) Accessory lobe of liver presenting symptoms of pelvic tumor. New Yorkes State Journal of Medicine, 69, 1334.

LloRENTE, J. \& DARDIK, H. (1971) Symptomatic accessory. lobe of liver associated with absence of the left lobe. $\overrightarrow{\vec{H}}$ Archives of Surgery, 102, 221.

LOTTEE, J. \& MADIER, G. (1960) Infarction caused by torsion? of accessory lobe of liver. Surgery cure. Presse Médicale, $68,838$.

MCGregor, A.L. (1950) Synopsis of Surgical Anatomy, ir 8th ed., p. 418. John Wright: Bristol. OMANIK, S. \& JABLONSKY, I. (1972) Pedunculated accessory
hepatic lobe. Archives of Surgery, 105, 792.

WATSON, J.R. \& LEE, R.E. (1964) Accessory lobe of liver withiN infarction. Archives of Surgery, 88, 490.

\title{
Chronic hepatitis in polymyalgia rheumatica
}

\author{
K. THOMPSON \\ M.A., M.B., B.Ch.
}

\author{
P. F. ROBERTS \\ M.B., M.R.C.P., M.R.C.Path.
}

Norfolk and Norwich Hospital, Norwich

\begin{abstract}
Summary
A review of the literature relating hepatic abnormalities with the giant cell arteritis, polymyalgia rheumatica syndrome is presented. A case of polymyalgia rheumatica with biochemical and histological abnormalities of the liver is described. It is suggested that a more detailed investigation of liver function should be made in patients with this syndrome where reasonably indicated.
\end{abstract}

\section{Introduction}

RECENTLY, attention has been focused on the association between polymyalgia rheumatica, giant cell arteritis and an elevated serum alkaline phosphatase with, or without, other evidence of hepatic dysfunction (Hall and Hargreaves, 1972; Glick, 1972; Dickson et al., 1973; Long and James, 1974). These findings have raised the possibility of an

Correspondence: Dr P. F. Roberts, Consultant Histopathologist, Norfolk and Norwich Hospital, Norwich NR1 3SR. association between liver disease and these two disorders. Long and James (1974) reported findingo granulomatous hepatitis in a single case of poly- $\frac{3}{2}$. myalgia rheumatica. A case with different histopathological changes in the liver is now reported.

\section{Case report}

A 77-year-old woman with a long history of은 psoriasis, presented 8 years ago with malaise and 7 severe pain in the muscles of the neck, back and proximal limb muscles. On examination, these muscles were tender to palpation and there was noevidence of psoriatic arthropathy. X-rays of the joints and chest were normal, the haemoglobin was $\omega$ $11 \mathrm{~g} / 100 \mathrm{ml}$ and the ESR $100 \mathrm{~mm}$ in $1 \mathrm{hr}$. Serological tests for gout and rheumatoid arthritis wereo negative. A diagnosis of polymyalgia rheumatica was $ळ$ made. The symptoms abated with oral prednisone ${ }^{+}$ therapy but the ESR remained elevated. Over the next 6 years she remained well apart from exacer- $\frac{\text { Pे }}{\mathbb{D}}$ bations of the disease when steroid withdrawal was $\stackrel{P}{\mathcal{P}}$ 
attempted. Two years ago she began to develop anorexia and lassitude and abdominal palpation revealed an enlarged liver. Liver function tests were: alkaline phosphatase $44 \mathrm{KA} \mathrm{u} / 100 \mathrm{ml}$ (normal range 4-14), aspartate transaminase (AST) 42 i.u./1 (normal range 0-27), alanine transaminase (ALT) 63 i.u./1 (normal range 4-24). Over the next 6 months, the liver function tests, having initially returned to normal values, again became abnormal. The ESR continued to be elevated at $69 \mathrm{~mm} / \mathrm{hr}$. At the end of the 6 months, prednisone therapy was stopped. The patient was then lost to follow-up until June, 1974, when she presented with depression, anorexia and recurrence of muscle pain.

On examination, she was jaundiced and had hepatomegaly and so she was admitted to hospital for investigation. She had had no injections in the previous 6 months and was receiving nitrazepam only. There was no history of excess alcohol ingestion. She had not been taking oral therapy for her psoriasis. The laboratory results were: bilirubin 1.9 $\mathrm{mg} / 100 \mathrm{ml}$ (direct $1.4 \mathrm{mg}$ ); alkaline phosphatase $80.5 \mathrm{KA} \mathrm{u} / 100 \mathrm{ml}$; AST 75 i.u./l; ALT 54 i.u./l; total protein $8.8 \mathrm{~g} / 100 \mathrm{ml}$ (normal 5.7-7.9); albumin $3.7 \mathrm{~g} / 100 \mathrm{ml}$ (normal $2 \cdot 5-5.0$ ); globulin $5.1 \mathrm{~g} / 100 \mathrm{ml}$ (normal 2.3-4.0); lactate dehydrogenase 760 i.u./l (normal 250-650); serum calcium and phosphate normal; urinary bilirubin and urobilinogen elevated; Wasserman reaction negative; Australia antigen negative; haemoglobin normal; ESR $93 \mathrm{~mm} / \mathrm{hr}$; bleeding time and coagulation studies normal; there were no LE cells and no antibodies to nuclei, mitochondria, smooth muscle, parietal cells, thyroid microsomes and thyroid colloid. A liver biopsy showed increased fibrosis in the portal tract with irregularity of the limiting plate (Fig. 1) with a lymphocytic and occasional polymorph and plasma cell exudate (Fig. 2). There was no bile duct proliferation and no granulomata were seen. Kupffer's cells were prominent and showed ceroid phagocytosis, indicating recent liver cell damage. Bile stasis was not a feature and there was no active cellular necrosis. There was no evidence of cirrhosis or fatty change. The appearances were considered to represent either a chronic persistent hepatitis or a stage in the development of primary biliary cirrhosis. In view of these findings and the patient's general symptomatic improvement, she was discharged from hospital but was not started on prednisone therapy. Two months later she was re-admitted to hospital with a fractured femur and the most recent liver function tests were: bilirubin $1.9 \mathrm{mg} / 100 \mathrm{ml}$ (direct 1.3); AST 50 i.u./l; ALT 34 i.u./l; alkaline phosphatase $101 \mathrm{KA} \mathrm{u} / 100$ $\mathrm{ml}$.

\section{Discussion \\ Undoubtedly, this is a case of polymyalgia rheumatica with chronic liver disease. Laboratory tests in previous cases (Dickson et al., 1973; Long and James, 1974) particularly with isoenzyme studies of alkaline phosphatase, suggest the presence of hepatic dysfunction with involvement of the biliary excretory system. In this case, although no mito- chondrial antibodies were present, the histological changes were more in favour of a disease process such as primary biliary cirrhosis rather than large duct obstruction or a hypersensitivity cholestatic reaction. In a recent review of liver diseases in}

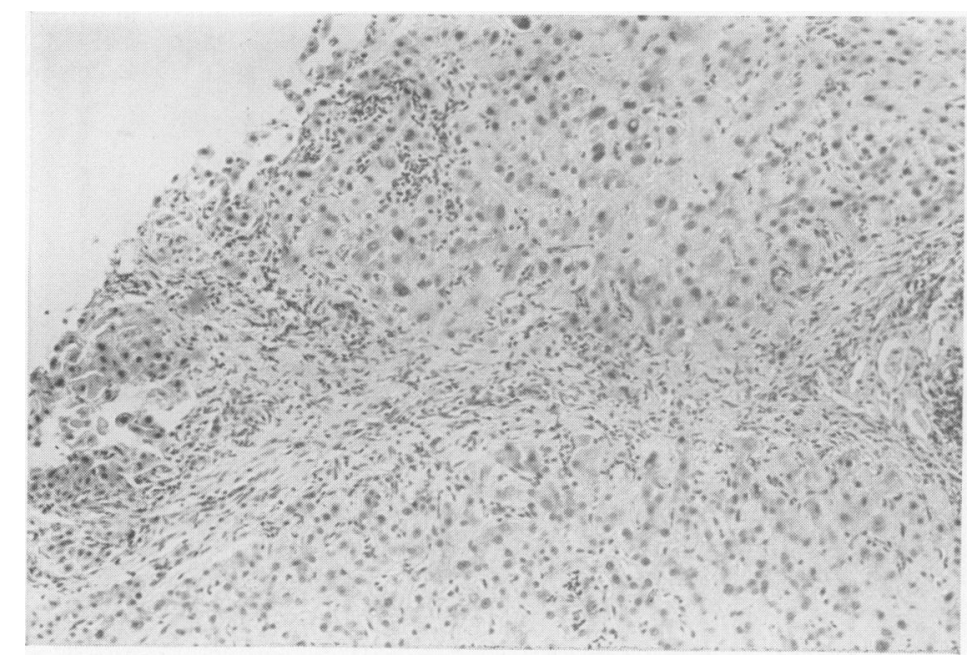

Fig. 1. The portal tract is enlarged owing to irregular fibrosis and there is an inflammatory exudate extending into the parenchyma. Haematoxylin and eosin $\times 90$. 


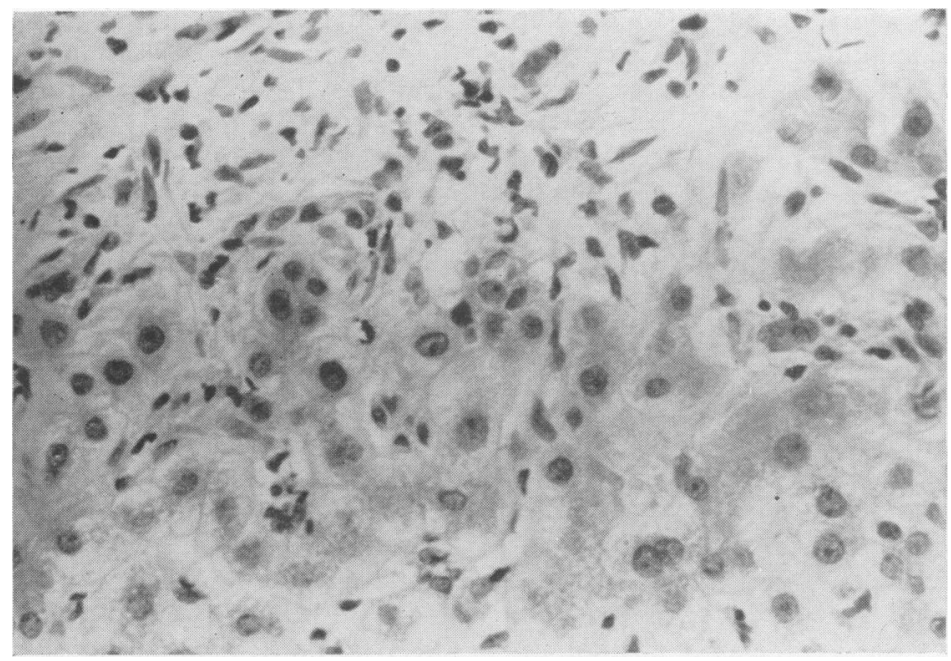

FIG. 2. Detail of the limiting plate showing the inflammatory exudate. Haematoxylin and eosin $\times 240$.

patients with joint symptoms (Hilton et al., 1974), attention was drawn to the importance of drugs in the disturbance of hepatic function, particularly salicylates, indomethacin, phenylbutazone, gold and azathioprine, all anti-rheumatic agents. The one case of giant cell arteritis included in the review showed hepatic dysfunction and this was believed to be due to azathioprine therapy. No liver biopsy was performed. Previous reports of histopathological changes in the liver have included two with normal appearances and two with fatty change (Dickson et al., 1973) and one with a granulomatous hepatitis (Long and James, 1974). There now seems to be a case for linking hepatic dysfunction with the polymyalgia rheumatica, giant cell arteritis syndrome. It is only by following up such cases with raised alkaline phosphatase levels, with liver biopsies wherereasonably indicated in these elderly patients, that full assessment of this complication can be made.

\section{References}

Dickson, E.R., Maldonado, J.E., Sheps, S.G. \& CaIRn, JA (1973) Systemic giant cell arteritis with polymyalojia rheumatica. Journal of the American Medical Association? 224, 1496.

GLICK, E.N. (1972) Raised serum alkaline phosphatase level in polymyalgia rheumatica. Lancet, ii, 328.

HALL, G.H. \& HaRgREAVES, T. (1972) Giant cell arteritis and raised serum alkaline phosphatase levels. Lancet, ii, 48.

Hilton, A.M., Boyes, B.E., Smith, P.J., SharP, J. \& Dymock? I.V. (1974) Liver disease in patients with joint symptoms? Annals of Rheumatic Diseases, 33, 540.

LoNG, R. \& JAMES, O. (1974) Polymyalgia and liver disease Lancet, i, 77. 